\title{
Utilization of Hiv/Aids Management Strategies by Pregnant Women in Antenatal Clinics in Abak, Nigeria
}

\author{
Grace Enomfon Akpan ${ }^{1 *}$, Ephraim Udo ${ }^{2}$ \\ ${ }^{1,2}$ Department of Physical and Health education, University of Uyo, Nigeria \\ *Corresponding Author: Grace Enomfon Akpan, Department of Physical and Health education, \\ University of Uyo, Nigeria
}

\begin{abstract}
The purpose of this study was to examine the extent of utilization of available HIV and AIDS management strategies among pregnant women attending antenatal clinic in maternal Child Health Midim, Abak Local Government Area in Akwa Ibom State, Nigeria. Four research questions and four hypotheses were formulated respectively to guide the study. The targeted population for the study comprised all pregnant women that attended antenatal clinic at Maternal Child health Midim, Abak from 2013-2016. According to the Hospital records, the number estimated was 2304 pregnant women that registered for antenatal within the period under study constituted the sample size for the study. Purposive sampling technique was used to select the sample size. A preview of the hospital records for the period under study was the main instrument used to collect data for the study. The research questions were answered and the hypotheses were tested. Simple percentage was adopted ton answer the research questions while Chi-square was adopted to test the hypotheses to determine their significance at 0.5 Alpha levels. The result from the study revealed that 413 representing 17.93 percent was the total number of pregnant women that utilized the available HIV and AIDS management strategies from January 2013 to December 2016 out of the total number of 2304 pregnant women who visited Maternal Child Health Midm, Abak for antenatal. The study also revealed that maternal age, occupation of women, educational level of the women and parity significantly influence the utilization of available HIV and AIDS management strategies by pregnant women in Abak Local Government Area. It was recommended among others that there is need to plan and implement new strategies of educating women particularly in rural areas who are at the lower education levels about HIV and AIDS modes of transmission and preventions.
\end{abstract}

Keywords: HIV/Aids, Antenatal, Management Strategies, Statistics

\section{INTRODUCTION}

The Human Immunodeficiency Virus (HIV) pandemic is one of the most serious health crisis the world faces today. AIDS has killed more than 23 million people since 1981 and an estimated 38.6 million people are now living with HIV, about 2.3 million are children [1]. From 1999, primarily as a result of HIV, average life expectancy is now 49 +.years- 13years less than in the absence of AIDS [2]. A disproportionate burden has been placed on women and children, who in many settings continue to experience high rates of new HIV infections and related illnesses and death.

In 2015 alone, an estimated 540,000 children were newly infected with HIV, with about 90 percent of these infections occurring in sub-Saharan Africa [3]. Most children living with HIV acquire the infection through mother-to-child transmission (MTCT), which can occur during pregnancy, labour and delivery or during breastfeeding. In the absence of any intervention the risk of such transmission is $15-30$ percent in non-breastfeeding populations. Breastfeeding by an infected mother increase the risk by $5-20$ percent to a total of 20-45 percent [4].

The risk of MTCT can be reduced to fewer than 2 percent by interventions that include anti-retroviral (ARV) prophylaxis given to women during pregnancy and labour and to the infant in the first weeks of life, obstetrical interventions including elective caesarean delivery (prior to the onset of labour and rupture of membranes), and complete avoidance of breastfeeding [5,6]. With these interventions, new HIV infections in children are becoming increasingly rare in many parts of the world, particularly in high-income countries. In many resource-constrained settings, elective caesarean delivery is seldom feasible [7] and is often neither acceptable nor safe for mothers to refrain from breastfeeding. 
Prevention of mother to child transmission of HIV and AIDS is a global need. The goal of PMTCT of HIV and AIDS is to stop HIV infected mothers from passing HIV to their children during pregnancy, labour, delivery and breastfeeding. PMTCT of HIV and AIDS programmes are designed for HIV positive pregnant mothers. It may also benefit uninfected women and women who do not know their HIV status. For uninfected mothers, they are counselled on how to maintain their HIV negative status, while women who do not know their HIV status are counselled to go for HIV testing, this would reveal their HIV status.

HIV/AIDS is a terminal disease. Although no permanent cure has been found, there is a provision of anti-retroviral drugs that assist in prolonging the lives of those who have been infected. Knowledge of one's HIV status is a first step to facilitate assessing care and preventing further infection, thereby controlling the HIV epidemic [8]. One of the strategies ascertaining one's HIV status is counselling and testing, Voluntary Counselling Testing (VCT). VCT for HIV is recognized globally as an effective and pivotal strategy for both prevention and management of HIV and AIDS [8].

Counselling and testing centres are places clients visit to know more about HIV/AIDS and confirm their sero status in order to make informed decision on their health and behaviour [9]

Some studies in Nigeria have revealed that there is poor knowledge of HIV and AIDS management strategies among traders despite the high awareness of the disease [10,11]. Thus, VCT services are an important avenue to receive important information about HIV and AIDS. This is further substantiated in a research carried out by Stephenson [11]; some of the women took the test but failed to return for the test results for various reasons.

However, in other studies, the majority (81\%) of the participants returned fro their test results following counselling and testing [12]. In Nigeria, Akwa Ibom State in particular, several campaigns have been mounted to increase awareness to HIV and AIDS. These include radio and television jingles, rallies, school HIV and AIDS clubs, campaigns mounted by Non-Governmental Organizations (NGOs) at community level, etc. These campaigns, started more than two decades ago, are yet to impact the HIV statistics significantly, although it seems to hover about the same level [13].

\section{EXPERIMENTALS}

\subsection{Research Methods}

This focuses on presenting the procedures adopted to arrive at dependable results in the investigation of the extent of utilization of available HIV and AIDS management strategies among pregnant women attending antenatal clinic in Maternal Child Health Midim Abak Local Government Area.

\subsection{Research Design}

The research design adopted for this study is the expost facto design. This design suit this study in that the researcher has no direct control over the variables under study and cannot manipulate the outcome and will only use the records in the hospital to describe the existing phenomena.

\subsection{Population for the Study}

The target population for this study includes all pregnant women attending antenatal clinic in Maternal Child Health, Midim Abak from 2013-2016. According to the hospital records the number is estimated to be 2304 pregnant women within this period.

\subsection{Sample and Sampling Techniques}

Based on the population for the study, all pregnant women that registered for antenatal within the period under study constituted the sample for the study. Purposive sampling technique was used to select the sample size for the study. Purposive sampling according to Odu and Ihejiamaizu [14] is characterized by the use of judgement and deliberate effort to obtain representative sample by including typical areas or groups in the selected sample. The main purpose of using this technique is to compose a sample that will yield research data, which can be applied to larger population.

\subsection{Instrument for Data Collection}

The main instrument for data collection in this was the preview of the hospital records for the period under study. Odu and Ihejiamaizu [14] noted that some of the instruments used in measuring causal 
comparative studies Expost facto include, standardized test, questionnaires, interview, participant observational techniques through long periods and medical history. In this study, the medical history of such women were used and all data in such records extracted for analysis.

\subsection{Validity and Reliability of the Instrument}

The instrument used for this study which is the hospital records is considered valid in that these records constitute the basis for which interventions have been planned for several issues and has been kept consistently for quite a long time.

\subsection{Methods of Data Collection}

The researcher, after obtaining permission from the hospital with an approved letter was given the hospital records to copy out the needed information without making photocopies in order to keep the confidentiality of their patients as prescribed by the profession. The researcher only collected information concerning the variables under study, such as age, occupation, parity and educational qualification.

\subsection{Methods of Data Analysis}

The data generated from the hospital records were analyzed with SPSS version 20 Software. Descriptive Statistics (percentages) was applied to answer the research questions and the Chi-square was used to test the hypotheses which were set at .05 level of significance.

\section{RESULTS AND DISCUSSION}

\subsection{Data Presentation and Analysis}

Results of data collected are presented in tables for easy comprehension. The data that formed the basis for this analysis were data generated from the hospital records for the period under study.

\subsection{Bio-Data of Subjects}

Table1. Subjects distribution by age

\begin{tabular}{|l|l|l|}
\hline \multicolumn{1}{|c|}{ Age range } & \multicolumn{1}{c|}{ No. of Subject } & \multicolumn{1}{c|}{ Percentage (\%) } \\
\hline $18-23$ & 790 & 34.29 \\
\hline $24-39$ & 984 & 42.71 \\
\hline $30-35$ & 395 & 17.14 \\
\hline 36 and above & 135 & 5.86 \\
\hline Total & $\mathbf{2 3 0 4}$ & $\mathbf{1 0 0}$ \\
\hline
\end{tabular}

Source: Hospital Records (2013-2016)

The above table shows that $790(34.29 \%)$ of the respondents were within the age range of 18-23 years, 984(42.71\%) were within 24-29 years, 395(17.14\%) were within 30-35 years while $135(5.86 \%)$ were within the age range of 36 and above. The age range having the highest frequency was 24-39 years with $984(42.71 \%)$ of the respondents.

Table2: Subjects distribution by Occupation.

\begin{tabular}{|l|l|l|}
\hline \multicolumn{1}{|c|}{ Occupation } & \multicolumn{1}{c|}{ No. of Subject } & \multicolumn{1}{c|}{ Percentage(\%) } \\
\hline Trading & 590 & 25.61 \\
\hline Farming & 1034 & 44.88 \\
\hline Civil servants & 324 & 14.06 \\
\hline Students & 41 & 1.78 \\
\hline Housewives & 315 & 13.67 \\
\hline Total & $\mathbf{2 3 0 4}$ & $\mathbf{1 0 0}$ \\
\hline
\end{tabular}

Source: Hospital Records(2013-2016)

The table shows that $590(25.62 \%)$ of the women were traders, $1034(44.88 \%)$ were farmers, 324 $(14.06 \%)$ were civil servants, while $41(1.78 \%)$ and $315(13.67 \%)$ were students and house wives respectively. It shows that most of the respondents were farmers as farming having the highest frequency of $1034(44.88 \%)$ of the respondents. 
Table3. Subjects distributed by level of education

\begin{tabular}{|l|l|l|}
\hline \multicolumn{1}{|c|}{ Education } & \multicolumn{1}{c|}{ No. of subject } & \multicolumn{1}{c|}{ Percentage(\%) } \\
\hline Primary & 891 & 38.67 \\
\hline Secondary & 1047 & 45.44 \\
\hline Tertiary & 366 & 15.89 \\
\hline Total & $\mathbf{2 3 0 4}$ & $\mathbf{1 0 0}$ \\
\hline
\end{tabular}

Source: Hospital Records (2013 - 2016)

The table above shows that $891(38.67 \%)$ of the women had primary education, $1047(45.44 \%)$ had secondary education while 366(15.89) had tertiary education. It shows that majority of the women had secondary education as secondary education having the highest frequency of 1047(45.44\%) of the respondents.

Table4. Subjects distributed by Parity

\begin{tabular}{|l|l|l|}
\hline \multicolumn{1}{|c|}{ Parity } & \multicolumn{1}{c|}{ No. of subject } & \multicolumn{1}{c|}{ Percentage(\%) } \\
\hline Primid & 218 & 9.46 \\
\hline$P_{1}$ & 861 & 37.37 \\
\hline$P_{2}$ & 457 & 19.84 \\
\hline$P_{3}$ & 312 & 13.54 \\
\hline$P_{4}$ & 263 & 11.41 \\
\hline$P_{5}$ & 106 & 4.60 \\
\hline$P_{6}$ & 87 & 3.78 \\
\hline Total & 2304 & 100 \\
\hline
\end{tabular}

Source: Hospital Records(2013-2016)

The above table shows that $218(9.46 \%)$ were pregnant for the first time, 861(37.37\%) had one child, 457(19.84\%) had two children, 312(13.54\%) had at least three children, 263(11,41\%) had four children while 106(4.60\%) and 87(3.78\%) had five and six children respectively.

Table5. Utilization of available HIV and AIDS management strategies among pregnant women from January 2013 - December 2016

\begin{tabular}{|l|l|l|}
\hline \multicolumn{1}{|c|}{$\begin{array}{c}\text { Years } \\
\text { Percent (\%) }\end{array}$} & \multicolumn{1}{c|}{ ANC Women } & \multicolumn{1}{c|}{ Service utilization } \\
\hline 2013 & 640 & 87 \\
13.59 & 658 & 106 \\
\hline 2014 & & 102 \\
16.11 & 543 & 118 \\
\hline 2015 & & \\
18.78 & 463 & $\mathbf{4 1 3}$ \\
\hline 2016 & & \\
25.49 & $\mathbf{2 3 0 4}$ & \\
\hline Total & & \\
$\mathbf{1 7 . 9 3}$ & &
\end{tabular}

Source: Hospital Records(2013-2016)

Data in the table above revealed that in 2013, 640 women attended antenatal at the MCH, Abak Local Government area and 87 women representing $13.59 \%$ utilized the service of the year. In 2014, out of the 658 pregnant women, 106 representing 16.11 percent utilized the service. In 2015 and 2016, 543 and 463pregnant women having 102 and 118 representing 18.78 and $25.49 \%$ respectively. However, 413 representing 17.93 percent was the total number of pregnant women that utilize the available HIV and AIDS management strategies from January 2013 - December 2016 out of the total number of 2304 pregnant women that registered for antenatal at $\mathrm{MCH}$, Abak.

\subsection{Answering of Research Question}

\subsubsection{Research Question 1}

What is the influence of maternal age on the utilization of available HIV and AIDS management strategies by pregnant women in Abak Local Government area? 
Table6. Cross tabulation of material age on the utilization of available HIV and AIDS management strategies

\begin{tabular}{|l|l|l|l|}
\hline \multicolumn{1}{|c|}{ Age } & \multicolumn{1}{c|}{ Pregnant women Service utilization } & \multicolumn{1}{c|}{ Non-utilization } & \multicolumn{1}{c|}{ Total } \\
\hline $18-23$ & $87(3.78 \%)$ & $703(30.51 \%)$ & $790(34.29 \%)$ \\
\hline $24-29$ & $112(4.86 \%)$ & $872(37.85 \%)$ & $984(42.71 \%)$ \\
\hline $30-35$ & $121(5.25 \%)$ & $274(11.89 \%)$ & $395(17.14 \%)$ \\
\hline $36-$ above & $93(4.04 \%)$ & $42(1.82 \%)$ & $135(5.86 \%)$ \\
\hline Total & $\mathbf{4 1 3}(\mathbf{1 7 . 9 3 \% )}$ & $\mathbf{1 8 9 1}(\mathbf{8 2 . 0 7 \%})$ & $\mathbf{2 3 0 4}(\mathbf{1 0 0 \%})$ \\
\hline
\end{tabular}

Source: Hospital Records(2013-2016)

The above table shows that 790 of the women were between the age bracket of $18-23$ years with 87 representing 3.78 percent utilizing the available HIV and AIDS management strategies and 703 representing 30.51 percent do not. The age bracket of $24-29$ years had 984 pregnant women with 112 representing 4.86 percent utilizing the service. Other ages of $30-35$ years and 36 years and above had $121(5.25 \%)$ and 93 (4.04\%) pregnant women utilizing the service respectively. The result shows that the utilization of the available HIV and AIDS management strategies increases with maternal age with the age bracket of $30-35$ years havin the highest number of 121 representing 5.25 per cent of the total pregnant women. This shows that here is a great interaction between maternal age and the utilization of the available HIV and AIDS management strategies.

\subsubsection{Research Question 2}

To what extent does the occupation influences the utilization of the available HIV and AIDS management strategies by pregnant women in Abak Local Government Area?

Table7. Cross tabulation of occupation on the utilization of available HIV and AIDS management strategies

\begin{tabular}{|l|l|l|l|}
\hline \multicolumn{1}{|c|}{ Occupation } & Pregnant women Service utilization & \multicolumn{1}{c|}{ Non-utilization } & \multicolumn{1}{c|}{ Total } \\
\hline Trading & $87(3.74 \%)$ & $503(21.83 \%)$ & $590(25.61 \%)$ \\
\hline Farming & $112(4.86 \%)$ & $922(40.02 \%)$ & $1034(44.88 \%)$ \\
\hline Civil servant & $103(4.47 \%)$ & $221(9.59 \%)$ & $324(14.06 \%)$ \\
\hline Student & $34(1.48 \%)$ & $7(0.30 \%)$ & $41(1.78 \%)$ \\
\hline House wife & $77(3.34 \%)$ & $238(10.33 \%)$ & $315(13.67 \%)$ \\
\hline Total & $\mathbf{4 1 3}(\mathbf{1 7 . 9 3 \% )}$ & $\mathbf{1 8 9 1}(\mathbf{8 2 . 0 7 \%})$ & $\mathbf{2 3 0 4}(\mathbf{1 0 0 \% )}$ \\
\hline
\end{tabular}

Source: Hospital Records(2013-2016)

Data in the above table shows that 590(25.61\%) were traders with only $87(3.78 \%)$ utilizing the available HIV and AIDS management strategies, 1034(44.88\%) were farmers with 112 (4.86\%) utilizing the service, 324(14.06\%) were civil servants with 103(4.47\%) utilizing the service, $41(1.78 \%)$ were students with $34(1.48 \%)$ utilizing the service and $315(13.67 \%)$ were house wives with $77(3.34 \%)$ utilizing the service. The result shows that occupation of the women influences their utilization of available HIV and AIDS management strategies services.

\subsubsection{Research Question 3}

To what extent does level of education of pregnant women in Abak Local Government area influences their utilization of available HIV and AIDS management strategies?

Table8. Cross tabulation of level of Education on the utilization of available HIV and AIDS management strategies.

\begin{tabular}{|l|l|l|l|}
\hline \multicolumn{1}{|c|}{ Education } & \multicolumn{1}{|c|}{ Pregnant women Service utilization } & \multicolumn{1}{c|}{ Non-utilization } & \multicolumn{1}{c|}{ Total } \\
\hline Primary & $97(4.22 \%)$ & $794(34.46 \%)$ & $891(38.67 \%)$ \\
\hline Secondary & $119(5.16 \%)$ & $928(40.28 \%)$ & $1047(45.44 \%)$ \\
\hline Tertiary & $197(8.55 \%)$ & $169(7.34 \%)$ & $366(15.89 \%)$ \\
\hline Total & $\mathbf{4 1 3}(\mathbf{1 7 . 9 3 \%})$ & $\mathbf{1 8 9 1}(\mathbf{8 2 . 0 7 \%})$ & $\mathbf{2 3 0 4}(\mathbf{1 0 0 \%})$ \\
\hline
\end{tabular}

Source: Hospital Records(2013-2016)

Data in the above table shows that $891(38.67 \%)$ had primary education with only $97(4.22 \%)$ utilizing the available HIV and AIDS management strategies, 1047(45.44\%) had secondary education with $119(5.16 \%)$ utilizing the available HIV and AIDS management strategies and 366(15.89\%) with 197(8.55\%) utilizing the available HIV and AIDS management strategies. The result shows that the 
influence of the level of education of the pregnant woman on the utilization of available HIV and AIDS management strategies services.

\subsubsection{Research Question 4}

How does parity influences the utilization of available HIV and AIDS management strategies by pregnant women in Abak Local Government area?

Table9. Cross tabulation of parity on the utilization of available HIV and AIDS management strategies

\begin{tabular}{|l|l|l|l|}
\hline \multicolumn{1}{|c|}{ parity } & \multicolumn{1}{c|}{ Pregnant women Service utilization } & \multicolumn{1}{c|}{ Non-utilization } & \multicolumn{1}{c|}{ Total } \\
\hline Primid & $114(4.95 \%)$ & $104(4.51 \%)$ & $218(9.46 \%)$ \\
\hline$P_{1}$ & $104(4.51 \%)$ & $757(32.86 \%)$ & $861(37.37 \%)$ \\
\hline$P_{2}$ & $78(3.39 \%)$ & $379(16.45 \%)$ & $457(19.84 \%)$ \\
\hline$P_{3}$ & $38(1.65 \%)$ & $274(11.89 \%)$ & $312(13.54 \%)$ \\
\hline$P_{4}$ & $34(1.48 \%)$ & $229(9.94 \%)$ & $263(11.41 \%)$ \\
\hline$P_{5}$ & $29(1.26 \%)$ & $77(3.34 \%)$ & $106(4.60 \%)$ \\
\hline$P_{6}$ & $16(0.69 \%)$ & $71(3.08 \%)$ & $87(3.78 \%)$ \\
\hline Total & $\mathbf{4 1 3}(\mathbf{1 7 . 9 3 \%})$ & $\mathbf{1 8 9 1}(\mathbf{8 2 . 0 7 \%})$ & $\mathbf{2 3 0 4}(\mathbf{1 0 0 \%})$ \\
\hline
\end{tabular}

Source: Hospital Records(2013-2016)

Data In the above table shows that $218(9.46 \%)$ were just pregnant for the first time with only 114(4.95\%) utilizing the available HIV and AIDS management strategies, 861(37.37\%) had one child each with 104(4.51\%) utilizing the available HIV and AIDS management strategies. Those that had two children had $78(3.39 \%)$ of them utilizing the services; those with three children had $38(1.65 \%)$ of them utilizing the services. Those with four children had 34(1.48\%) of them utilizing the services. Parity of five had $29(1.26 \%)$ of them utilizing the services and those with six children had only $87(3.78 \%)$ with $16(0.69 \%)$ of them utilizing the services. The result shows that the level of utilization of available HIV and AIDS management strategies decreases with the number of parity six having the lowest number of $16(0.69 \%)$, followed by parity of five with 29 representing 1.26 per cent.

\subsection{Test of Hypothesis}

\subsubsection{Hypothesis 1}

This hypothesis states that there is no significant influence of maternal age on the utilization of available HIV and AIDS management strategies by pregnant women in Abak Local Government Area. The test of this hypothesis is presented in the table below:

Table10. Summary of $2 \times 4$ contingency of maternal age and utilization of available HIV and AIDS management strategies

\begin{tabular}{|l|l|l|l|l|l|l|l|}
\hline \multicolumn{1}{|c|}{ Age } & \multicolumn{2}{|c|}{ Pregnant women Service utilization } & \multicolumn{2}{c|}{ Non-utilization } & Total & $\chi^{2}$-cal & $\chi^{2}$-crit \\
\hline & \multicolumn{1}{|c|}{ fo } & \multicolumn{1}{c|}{$\mathbf{f e})$} & $\mathbf{f o}$ & $\mathbf{( f e )}$ & & & \\
\hline $18-23$ & 87 & $(142)$ & 703 & $(648)$ & 790 & & \\
\hline $24-29$ & 112 & $(176)$ & 872 & $(808)$ & 984 & & \\
\hline $30-35$ & 121 & $(71)$ & 274 & $(324)$ & 395 & 17.02 & 8.04 \\
\hline 36 and above & 93 & $(24)$ & 42 & $(111)$ & 135 & & \\
\hline Total & $\mathbf{4 1 3}$ & $\mathbf{( 4 1 3 )}$ & $\mathbf{1 8 7 1}$ & $\mathbf{( 1 8 9 1 )}$ & $\mathbf{2 3 0 4}$ & & \\
\hline
\end{tabular}

$d f=3 ; P \leq .05$

The above result shows that the $\chi^{2}$ calculated value of 17.02 is greater than the $\chi^{2}$ critical value of 8.04 at .05 level of significance and a degree of freedom of 3 . This result is significant. Therefore, the null hypothesis is rejected meaning, maternal age has a significant influence on the utilization of available HIV and AIDS management strategies by pregnant women in Abak Local Government Area.

\subsubsection{Hypothesis 2}

The null hypothesis states that there is no significant influence of occupation on the utilization of available HIV and AIDS management strategies by pregnant women in Abak Local Government Area. This hypothesis was tested at .05 level of significance using contingency Chi-square and the result is presented in the table below: 
Table11. Summary of $2 \times 5$ contingency of occupation and utilization of available HIV and AIDS management strategies

\begin{tabular}{|l|l|l|l|l|l|l|l|}
\hline Occupation & \multicolumn{2}{|l|}{ Pregnant women Service utilization } & \multicolumn{2}{|l|}{ Non-utilization } & Total & $\boldsymbol{\chi}^{2}$-cal & $\chi^{\mathbf{2}}$-crit \\
\hline & fo & $\mathbf{f e})$ & $\mathbf{f o}$ & $\mathbf{( f e )}$ & & & \\
\hline Trading & 87 & $(106)$ & 504 & $(484)$ & 590 & & \\
\hline Farming & 112 & $(185)$ & 922 & $(849)$ & 1034 & & \\
\hline Civil servant & 103 & $(58)$ & 221 & $(266)$ & 324 & 18.32 & 9.49 \\
\hline Student & 34 & $(7)$ & 7 & $(34)$ & 41 & & \\
\hline House wife & 77 & $(56)$ & 238 & $(259)$ & 315 & & \\
\hline Total & $\mathbf{4 1 3}$ & $\mathbf{( 4 1 2 )}$ & $\mathbf{1 8 9 1}$ & $\mathbf{( 1 8 9 2 )}$ & $\mathbf{2 3 0 4}$ & & \\
\hline
\end{tabular}

$d f=4 ; P \leq .05$

The above result showed that the $\chi^{2}$ calculated value of 18.32 is greater than the $\chi^{2}$ critical value of 9.49 at .05 level of significance and a degree of freedom of 4 . This result is significant. Therefore, the null hypothesis is rejected meaning, occupation has significant influence on the utilization of available HIV and AIDS management strategies by pregnant women in Abak Local Government Area.

\subsubsection{Hypothesis 3}

The null hypothesis states that there is no significant influence of level of education on utilization of available HIV and AIDS management strategies by pregnant women in Abak Local Government Area. This hypothesis was tested at .05 level of significance using contingency chi-square and the result is presented in the table below:

Table12. Summary of $2 \times 3$ contingency of Education and utilization of available HIV and AIDS management strategies

\begin{tabular}{|l|l|l|l|l|l|l|l|}
\hline Education & Pregnant women Service utilization & \multicolumn{2}{|l|}{ Non-utilization } & Total & $\boldsymbol{\chi}^{2}$-cal & $\boldsymbol{\chi}^{\mathbf{2}}$-crit \\
\hline & fo & $\mathbf{( f e )}$ & $\mathbf{f o}$ & $\mathbf{( f e )}$ & & & \\
\hline Primary & 97 & $(160)$ & 794 & $(731)$ & 891 & & \\
\hline Secondary & 119 & $(188)$ & 928 & $(859)$ & 1047 & 20.12 & 8.34 \\
\hline Tertiary & 197 & $(66)$ & 169 & $(300)$ & 366 & & \\
\hline Total & $\mathbf{4 1 3}$ & $\mathbf{( 4 1 4 )}$ & $\mathbf{1 8 9 1}$ & $\mathbf{( 1 8 9 0 )}$ & $\mathbf{2 3 0 4}$ & & \\
\hline
\end{tabular}

$d f=2 ; P \leq .05$

The above result showed that the $\chi^{2}$ calculated value of 20.12 is greater than the $\chi^{2}$ critical value of 8.34 at .05 level of significance and a degree of freedom of 2 . This result is significant. Therefore, the null hypothesis is rejected which states that there is no significant influence of level of education on utilization of available HIV and AIDS management strategies by pregnant women in Abak Local Government Area is rejected, while the alternate hypothesis which states that there is significant influence of level of education on the utilization of available HIV and AIDS management strategies by pregnant women in Abak Local Government Area is accepted.

\subsubsection{Hypothesis 4}

The null hypothesis states that there is no significant influence of parity on the utilization of available HIV and AIDS management strategies by pregnant women in Abak Local Government Area. This hypothesis was tested at .05 level of significance using contingency Chi-square and the result is presented in the table below:

Table13. Summary of $2 x 7$ contingency of parity and utilization of available HIV and AIDS management strategies

\begin{tabular}{|l|l|l|l|l|l|l|l|}
\hline \multicolumn{1}{|c|}{ parity } & \multicolumn{2}{|c|}{ Pregnant women Service utilization } & \multicolumn{1}{c|}{ Non-utilization } & Total & $\chi^{2}$-cal & $\chi^{2}$-crit \\
\hline fo & \multicolumn{1}{|c|}{ fo } & \multicolumn{1}{c|}{ (fe) } & & & \\
\hline Primid & 114 & $(39)$ & 104 & $(179)$ & 218 & & \\
\hline$P_{1}$ & 104 & $(154)$ & 757 & $(707)$ & 861 & & \\
\hline$P_{2}$ & 78 & $(82)$ & 379 & $(375)$ & 457 & & \\
\hline$P_{3}$ & 38 & $(56)$ & 274 & $(256)$ & 312 & 143.33 & 14.07 \\
\hline$P_{4}$ & 34 & $(47)$ & 229 & $(216)$ & 263 & & \\
\hline$P_{5}$ & 29 & $(19)$ & $\mathbf{7 7}$ & $\mathbf{( 8 7 )}$ & $\mathbf{1 0 6}$ & & \\
\hline$P_{6}$ & 16 & $(16)$ & 71 & $\mathbf{( 7 1 )}$ & $\mathbf{8 7}$ & & \\
\hline Total & $\mathbf{4 1 3}$ & $\mathbf{( 4 1 3 )}$ & $\mathbf{1 8 9 1}$ & $\mathbf{( 1 8 9 1 )}$ & $\mathbf{2 3 0 4}$ & & \\
\hline
\end{tabular}

$d f=6 ; P \leq .05$

International Journal of Sports and Physical Education (IJSPE) 
The above result showed that the $\chi^{2}$ calculated value of 143.33 is greater than the $\chi^{2}$ critical value of 14.07 at .05 level of significance and a degree of freedom of 6 . This result is significant. Therefore, the null hypothesis is rejected meaning, parity significantly influences the utilization of available HIV and AIDS management strategies by pregnant women in Abak Local Government Area.

\subsection{Major Findings of the Study}

The following were the major discoveries in the course of this study:

There is a great interaction between maternal age and the utilization of the available HIV and AIDS management strategies by pregnant women in Abak Local Government Area. The test of the hypothesis yielded a significant result.

Occupation has a significance influence on the utilization of available HIV and AIDS management strategies by pregnant women in Abak Local Government Area

There is significance influence of education on the utilization of available HIV and AIDS management strategies by pregnant women in Abak Local Government Area

Parity has a significant in influence on the utilization of available HIV and AIDS management strategies by pregnant women in Abak Local Government Area.

\section{DISCUSSION OF FINDINGS}

The result from the study revealed that 413 representing 17.93 percent was the total number of pregnant women that utilized the available HIV and AIDS management strategies from January 2013 - December 2016 out of the total number of 2304 pregnant women who visited MCH, Abak for antenatal. The study however revealed that maternal age plays a significant role in the utilization of available HIV and AIDS management strategies by pregnant women in Abak Local Government Area. This result is in line with the study by [15] which revealed that women who were less than 20 years of age were more likely to accept HIV testing. HIV prevalence was higher among women greater than 30 years old(16.4\% HIV - positive vs. 5.3\% HIV - positive in teenagers). In the same vein, Bajunirwe and Muzoora [16] reported than the older pregnant women, the more utilization of the HIV and AIDS management strategies by them. This is because women who were greater than 30 years old were most likely to enrol in the programme.

The study further revealed that the occupation of women has a significant influence on the utilization of available HIV and AIDS management strategies by pregnant women in Abak Local Government Area. The finding of this study is in agreement with Uwameiye [17] postulation which states that the income level of any family is directly related to the kind of job or occupation the family is involved in and this is influenced by the level of education of the family and previous family background. The nature of occupation has implication on women access to HIV/AIDS information vis-à-vis utilization..

The study also revealed that educational level of the women significantly influence the utilization of available HIV and AIDS management strategies by pregnant women in Abak Local Government Area as those with higher level education show higher utilization of the service. This result is consistent with Stanfield and Bwibo [18] who argued that there is a strong correlation between level of education and utilization of healthcare service by the pregnant women as women who have attained the higher level of education, utilizes any healthcare service for the benefit of both themselves and their children..

Finally, the result also revealed a significant influence of parity on the utilization of available HIV and AIDS management strategies among pregnant women in Abak Local Government Area with the highest utilization among women who were pregnant for the first time having 4.95 per cent out of the 17.93 per cent of women that utilized the services. The test of the hypothesis also yielded a significant result of 143.33 at .05 level of significance and degree of freedom of 6 . This result seems to agree with the study conducted by Kasenga, Hurtig and Emmelin [19] who observed that the more children pregnant women had before their present pregnancy the less utilization of healthcare facilities before and during delivery and that all women who delivered in the hospital took their NVP tablets. Similarly, Campbell [10] reported that the utilization of healthcare facilities is more common in primigravadae women than those who already had two or more children before their present pregnancy. 


\section{CONCLUSION AND RECOMMENDATION}

The purpose of the study was to examine the extent of utilization of available HIV/AIDS management strategies among pregnant women attending antenatal clinic in MCH Midim, Abak Local Government Area. Several related literature were reviewed under theoretical, conceptual and analytical frameworks. Four research questions and four hypotheses were formulated respectively to guide the study.

The total population used for the study comprised all pregnant women that attended antenatal clinic at $\mathrm{MCH}$, Abak from 2013 - 2016. According to the hospital records, the number estimated was 2304 pregnant women. Based on the population for the study, all pregnant women tat registered for antenatal within the period under study constituted the sample size for the study. Purposive sampling technique was used to select the sample size.

A review of the hospital records for the period under the study was the main instrument used to collect data for the study. The research questions were answered and the hypotheses were tested. Simple percentage was adopted to answer the research questions while Chi-square was adopted to test the hypotheses to determine their significance at .05level of significance.

The result from the study revealed that 413 representing 17.93 percent was the total number of pregnant women that utilized the available HIV and AIDS management strategies from January 2013 - December 2016 out of the total number of 2304 pregnant women who visited MCH, Abak for antenatal. The study also revealed that maternal age, occupation of women, educational level of the women and parity significantly influence the utilization of available HIV and AIDS management strategies by pregnant women in Abak Local Government Area.

Having reviewed related literatures, collected and analysed data, this study has been able to reveal that the maternal age, occupation, level of education and parity significantly influence the utilization of available HIV and AIDS management strategies by pregnant women in Abak Local Government Area. This in line with the idea that there are certain factors that influences the utilization of most of the available healthcare services.

\section{REFERENCES}

[1] World Health Organization (2015). Scaling-up HIV testing and counselling services - a toolkit for program managers. Available on http://www.who.int/htm/en. (Accessed 12th may, 2017).

[2] Winstone, R.A.(2009). Infant feeding options in the context of HIV. Washingston DC: Academy for Educational Development

[3] Odesola, I.F., \& Babatunde,D.A. (2015) career awareness training and self-efficacy intervention technique in enhancing the career interest of female adolescents in male dominated occupations. Nigeria Journal of Applied Psychology, 5(1): 74-92.

[4] World Health Organization(2013). Increasing Access to HIV Testing and Counseling: Report of a WHO Consultation, 19-21 November 2012 Geneva.

[5] Hirschorn, J.P., Bisola, E.J., \& William A.(2007). Perinatal transmission of human immunedeficiency virus types 1 by pregnant women with RNA virus load. J Infect Dis: 183, 539-545.

[6] WHO (2010). Antiretroviral drugs for treating pregnant women and preventing HIV infection in infants in resource-limited settings. Geneva. Available on www.who.int/hiv/pub/mtct/ guidelines/ en. Accessed $5^{\text {th }}$ April, 2017.

[7] Chukurah, L.C., Idowu, A., \& Okoro, A.S. (2004). HIV/AIDS in un-saharan African. CMJ:45(4), 402-414

[8] Donkor, E.S. (2012). Knowledge, attitudes and practices of voluntary counselling and testing for HIV among pregnant women. Global Advanced Research Journal of Social Science, 1(2), 41-46.

[9] Ezeiru, S.S., \& Odeyemi, K.A. (2013). Reducing HIV - related stigma among pregnant women in Imo state through HIV education. Journal of Community Medicine and Primary Health care 24 (1\&2): 34-43.

[10] Campbell, P.C., Bamgbala, A.O. (2004). Awareness of HIV/AIDS among pregnant women in an urban area. Global Advanced Research Journal of Social Science, 14(2): 147-150.

[11] Stephenson, R. (2009). Community factors shaping HIV-related stigma among young people in three African countries. AIDS care, 21(4):403-410

[12] Ayodele, K.O. (2013). Psychological inclinations associated with adolescents' sexual behaviour: the moderating effect of gender. British Journal of Health Science, 6(1), 50-60. 
[13] UNAIDS Global report(2012). UNAIDS Report on global AIDS epidemic 2012: 9-14. Available on www.unaids.org/2012UNAIDS. Global report 2012 pdf. (Accessed $5^{\text {th }}$ April, 2017).

[14] Odu, E.N. \& Ihejiamaizu, E.C. (2001). Statistics and basic research methods in education and social sciences. Statistics and basic research methods in education and social sciences.University of Calabar

[15] Magoni M, Bassani L, Okong P, et al. Mode of infant feeding and HIV infection in children in a program for prevention of mother-to-child transmission in Uganda. AIDS 2005;19:433-7.

[16] Bajunirwe, F. and Muzoora, M. (2005) Barriers to the implementation of programs for the prevention of mother to child transmission of HIV: A cross sectional survey in rural and urban Uganda. AIDS Research and Therapy, 2, 10. doi:10.1186/1742-6405-2-10

[17] Uwameiye, R. (2004). Technical Education; A foundation for Technological Development. Abraka Journal of Education 6(2), 16-22.

[18] J. Paget Stanfield and Nimrod Bwibo Child Health (3rd Edition) The African Medical and Research Foundation (AMREF) ISBN No 9966-874-66-6

[19] Kasenga $\mathrm{F}^{1}$, Hurtig AK, Emmelin M. HIV-positive women's experiences of a PMTCT programme in rural Malawi. Midwifery. 2010 Feb;26(1):27-37. doi: 10.1016/j.midw.2008.04.007. Epub 2008 Jun 20.

Citation: Grace Enomfon Akpan, Ephraim Udo. " Utilization of Hiv/Aids Management Strategies by Pregnant Women in Antenatal Clinics in Abak, Nigeria "International Journal of Sports and Physical Education (IJSPE), vol 5, no. 2, 2019, pp. 13-22. doi:http://dx.doi.org/10.20431/2454-6380.0502002.

Copyright: (C) 2019 Authors. This is an open-access article distributed under the terms of the Creative Commons Attribution License, which permits unrestricted use, distribution, and reproduction in any medium, provided the original author and source are credited. 